\title{
High Plasma Brain Natriuretic Peptide Levels in Stable COPD without Pulmonary Hypertension or Cor Pulmonale
}

\author{
Yuzuru Inoue, Tomotaka Kawayama, Tomoaki Iwanaga and Hisamichi Aizawa
}

\begin{abstract}
Background Early diagnosis of chronic obstructive pulmonary disease (COPD) with latent pulmonary hypertension $(\mathrm{PH})$ and cor pulmonale is important because the prognosis of this condition is poor.

Objective To investigate the utility of brain natriuretic peptide (BNP) for prognostication of COPD, plasma BNP was measured in patients with COPD without symptoms or physical findings of $\mathrm{PH}$ or cor pulmonale.

Methods Plasma BNP was measured in 60 patients with COPD, 10 asthmatics, and 30 healthy subjects. Echocardiography, arterial blood gas analysis, and spirometry were also performed. Mortality and exacerbation were compared between COPD patients with high and low plasma BNP levels over a 3-year follow-up period.

Results Plasma BNP (mean \pm SEM, pg/mL) in COPD patients (41.0 \pm 6.6$)$ was significantly higher than in normal subjects $(14.8 \pm 2.7)$ and asthmatics $(17.4 \pm 4.5)(\mathrm{p}<0.0001$ and $\mathrm{p}<0.05$, respectively). No significant correlations were observed between plasma BNP level and pulmonary function or hypoxia. There was, however, a significant correlation between plasma BNP level and \% ejection fraction $(r=-0.41, p=0.0197)$ and pulmonary artery systolic pressure $(\mathrm{r}=0.5, \mathrm{p}=0.004)$. The period until initial COPD exacerbation in subjects with a high plasma BNP level was significantly shorter $(\mathrm{p}<0.05)$. Plasma BNP level during exacerbations $(79.9 \pm 16.2)$ was also significantly higher than during stable disease $(41.2 \pm 8.7)(\mathrm{p}=0.004)$.

Conclusion We suggest that plasma BNP is a non-invasive biomarker that can be used as a screening parameter for latent $\mathrm{PH}$ and left ventricular dysfunction, and also as a predictor of exacerbation in stable COPD.
\end{abstract}

Key words: chronic obstructive pulmonary disease, brain natriuretic peptide, pulmonary hypertension, cor pulmonale

(Inter Med 48: 503-512, 2009)

(DOI: 10.2169/internalmedicine.48.1701)

\section{Introduction}

In order to improve the outcome of patients with chronic obstructive pulmonary disease (COPD), early diagnosis and intervention for comorbidities are important (1). Previous large trials have suggested that the most frequent of cause of death in patients with COPD is cardiac, rather than respiratory complication $(2,3)$. Secondary pulmonary hypertension (PH) and cor pulmonale are also important causes of death and poor prognosis in COPD $(4,5)$. Therefore, early detection of $\mathrm{PH}$ or cor pulmonale is beneficial for the management of patients with COPD.
Right heart catheterization has been used for diagnosis and assessment of the severity of $\mathrm{PH}$ and cor pulmonale. However, recent studies have not demonstrated any sustained benefits of right heart catheterization for the monitoring of heart failure, and some have even suggested harm due to adverse events related to this invasive procedure $(6,7)$.

Plasma brain natriuretic peptide (BNP) is a useful noninvasive biomarker for the diagnosis and monitoring of cardiac diseases and heart failure $(8,9)$. In addition, it is well known that plasma BNP levels are elevated in patients with secondary $\mathrm{PH}$ and chronic lung disease with right ventricular overload (10-13).

Patients who have stable COPD without significant PH or 
cor pulmonale have not been studied, although it has been reported that an increased BNP concentration is a risk factor for death independent of chronic lung disease (14). The aim of the present study was to investigate the utility of the plasma BNP level as an indicator of prognosis in patients with stable and exacerbated COPD, who had no significant symptoms or physical evidence of $\mathrm{PH}$ and cor pulmonale. We also performed a 3-year prospective follow-up study.

\section{Methods}

\section{Subjects}

Subjects aged 40 years and over were enrolled in this study. Patients with other chronic respiratory diseases such as interstitial pneumonia, old pulmonary tuberculosis, bronchiectasis, and pneumoconiosis were carefully excluded, as were patients with a history of symptoms and medication for cardiac, renal, neurological and psychological diseases, and active malignancies.

Thirty normal subjects (non-smokers $n=17$; former smokers (smoking index $>10$ pack-years) $n=13$ ), 60 COPD patients and 10 asthmatic patients were enrolled in this study. The numbers of patients with mild, moderate, severe, and very severe COPD were $12,21,16$, and 11 , respectively (Table 1). Patients with severe and very severe COPD were significantly older than patients in the other groups $(\mathrm{p}<$ 0.05 ), and the percentage reversibility in $\mathrm{FEV}_{1}$ from pre- to post-bronchodilators, the absolute number of peripheral eosinophils, and the level of serum immunoglobulin E (IgE) in the asthmatic patients were significantly higher than in the other groups $(\mathrm{p}<0.05)$. The mean concentration of serum $\mathrm{C}$-reactive protein (CRP) in the COPD patients was higher than that in the normal and asthmatic subjects $(\mathrm{p}<0.001)$. Mean $\mathrm{PaO}_{2}$ in patients with severe and very severe COPD was significantly lower than in the other groups $(\mathrm{p}<0.05)$.

\section{Definition of COPD}

COPD patients with a smoking index of $>10$ pack-years and respiratory symptoms related to COPD were enrolled. COPD was diagnosed and its severity assessed in accordance with the Global Initiative for Chronic Obstructive Lung Disease (GOLD) 2006 guidelines (1). To examine the utility of the plasma BNP level in patients with stable COPD, those with associated definitive cardiac diseases, congestive heart failure, $\mathrm{PH}$ and cor pulmonale were excluded. Subjects with COPD who had symptoms or a history of edema, ascites, and dilatation of the jugular vein, or signs of hepato-splenomegaly were also excluded.

\section{Definition of severe asthma}

For comparison with COPD patients, non-smoking patients with persistent severe asthma were selected as matched controls. Asthma was diagnosed in accordance with the Global Initiative for Asthma (GINA) 2006 guidelines (15). Severe persistent asthma was defined as reported by
Wenzel (16). All asthmatics had persistent airway obstruction defined as a forced expiratory volume in 1 second $\left(\mathrm{FEV}_{1}\right)$ of $<80 \%$ of predicted and diurnal peak expiratory flow variability $>20 \%$, or had often required oral corticosteroids, despite regular combination therapy with high-dose inhaled corticosteroid, long-acting beta agonists and leukotriene antagonists in the last 12 months. Asthmatic subjects with cardiac diseases were excluded.

Abbreviation: \%: percent

\section{Study design}

All procedures used in this study were approved by the ethics committees of Kurume University. Each subject provided medical information including history of admissions for COPD exacerbation, physical examination, blood tests, chest X-ray, chest computed tomography, arterial blood gas analysis, echocardiography and spirometry after informed consent had been obtained. Arterial blood was drawn from 51 COPD patients after being sedentary for 10 minute breathing room air. Arterial oxygen partial pressure $\left(\mathrm{PaO}_{2}\right)$ was measured immediately using an automatic blood gas analyzer (Omni $\mathrm{C}^{\circledR}$, Roche Diagnostics Co., Tokyo, Japan). To evaluate respiratory failure in the remaining 9 COPD patients, oxygen saturation was measured using a pulse oximeter (PULSOX-300i ${ }^{\circledR}$, Konica Minolta Sensing Inc., Osaka, Japan), because informed consent for arterial blood gas analysis could not be obtained.

Peripheral blood was drawn from 09:00 to 12:00 hour and the samples were examined immediately. The absolute number of peripheral blood eosinophils was calculated using an automatic cell sorting system (XE-2100, Sysmex TMC Co., Kobe, Japan). The concentration of serum "CRP" was measured using a latex immunoturbidimetric assay kit (Iatro CRP-Ex $^{\circledR}$, Mitsubishi Kagaku Iatron Co., Chiba, Japan). Serum total "IgE" levels were measured using a chemiluminescence enzyme immunoassay kit (DPC-Immulyze Total IgE III $^{\circledR}$, Mitsubishi Kagaku Iatron Co.). Plasma BNP levels were measured from fresh peripheral blood in $1.5 \mathrm{mg} / \mathrm{mL}$ EDTA-1Na using an immuno-enzymometric assay kit (E test (TOSOH) II BNP ${ }^{\circledR}$, Tosoh Co., Tokyo, Japan). The lower limits of detection were $1 \mathrm{mg} / \mathrm{mL}, 1 \mathrm{IU} / \mathrm{mL}$, and $4 \mathrm{pg} / \mathrm{mL}$, for $\mathrm{CRP}$, IgE, and BNP, respectively. Values below these were assigned half the value of the lowest detectable limit for purposes of statistical analysis.

All subjects with COPD were followed for 3 years prospectively after all examinations had been completed. Each subject visited the hospital every 4 weeks. Plasma BNP levels were measured immediately (within a mean of 4 days) if exacerbation occurred during follow-up. The severity of exacerbation was classified as described by Rodriguez-Roisin (17). We also contacted all subjects or their families after 3 years to investigate death or survival.

Abbreviations: IU/mL: international unit per milliliter, $\mathrm{mg} /$ $\mathrm{mL}$ : milligram per milliliter, $\mathrm{pg} / \mathrm{mL}$ : picogram per milliliter 
Table 1. Characteristics of Subjects

\begin{tabular}{|c|c|c|c|c|c|c|c|}
\hline \multirow[b]{2}{*}{ Characteristics } & \multicolumn{2}{|c|}{ Normal control } & \multicolumn{4}{|c|}{ COPD } & \multirow[b]{2}{*}{ Asthma } \\
\hline & $\begin{array}{l}\text { Non- } \\
\text { smoker }\end{array}$ & Smoker & Stage I & Stage II & Stage III & Stage IV & \\
\hline Number & 17 & 13 & 12 & 21 & 16 & 11 & 10 \\
\hline Age, yr & $68.4(1.6)$ & $67.0(2.4)$ & $64.6(3.3)$ & $69.8(1.9)$ & $72.0(1.5)$ & $73.7(1.2)$ & $69.3(3.5)$ \\
\hline Gender, M/F & $9 / 8$ & $12 / 1$ & $9 / 3$ & $21 / 0$ & $13 / 3$ & $10 / 1$ & $5 / 5$ \\
\hline Smoking status, N/C/Ex & $17 / 0 / 0$ & $0 / 4 / 9$ & $0 / 7 / 5$ & 0/10/11 & $0 / 9 / 7$ & $0 / 1 / 10$ & $10 / 0 / 0$ \\
\hline Smoking index, pack-year & $0(0)$ & $37.5(7.6)$ & $43.7(9.2)$ & $65.0(7.6)$ & $61.0(8.3)$ & $49.4(7.6)$ & $0(0)$ \\
\hline Body mass index, $\mathrm{kg} / \mathrm{m}^{2}$ & $24.1(0.8)$ & $24.5(0.7)$ & $22.9(1.0)$ & $21.7(0.8)$ & $21.1(0.9)$ & $20.4(1.1)$ & $23.8(1.0)$ \\
\hline \multicolumn{8}{|l|}{ Spirometry, mean (SEM) } \\
\hline \multicolumn{8}{|l|}{ pre-bronchodilator } \\
\hline \multirow[t]{2}{*}{ FVC, L } & 3.38 & 3.65 & 3.72 & 3.21 & 2.57 & 2.36 & 2.40 \\
\hline & $(0.20)$ & $(0.22)$ & $(0.22)$ & $(0.12)$ & $(0.20)$ & $(0.20)$ & $(0.27)$ \\
\hline \multirow[t]{2}{*}{$\mathrm{FEV}_{1}, \mathrm{~L}$} & 2.56 & 2.65 & 2.33 & 1.73 & 0.91 & 0.79 & 1.34 \\
\hline & $(0.14)$ & $(0.14)$ & $(0.13)$ & $(0.08)$ & $(0.06)$ & $(0.11)$ & $(0.13)$ \\
\hline $\mathrm{FEV}_{1} / \mathrm{FVC}, \%$ & $76.5(1.4)$ & $73.2(1.8)$ & $63.0(1.1)$ & $53.9(1.6)$ & $36.7(2.0)$ & $34.7(4.5)$ & $57.2(3.3)$ \\
\hline \multirow[t]{2}{*}{$\% \mathrm{FEV}_{1}, \%$} & 110.4 & $95.2(3.5)$ & $89.8(2.8)$ & $63.0(2.5)$ & $38.9(2.0)$ & $31.1(4.1)$ & $61.0(4.1)$ \\
\hline & (5.1) & & & & & & \\
\hline \multicolumn{8}{|l|}{ post-bronchodilator } \\
\hline \multirow[t]{2}{*}{ FVC, L } & 3.38 & 3.71 & 3.71 & 3.25 & 2.75 & 2.49 & 2.43 \\
\hline & $(0.21)$ & $(0.21)$ & $(0.23)$ & $(0.13)$ & $(0.18)$ & $(0.19)$ & $(0.26)$ \\
\hline \multirow[t]{2}{*}{$\mathrm{FEV}_{1}, \mathrm{~L}$} & 2.60 & 2.80 & 2.37 & 1.78 & 0.98 & 0.85 & 1.52 \\
\hline & $(0.15)$ & $(0.14)$ & $(0.14)$ & $(0.08)$ & $(0.05)$ & $(0.11)$ & $(0.13)$ \\
\hline $\mathrm{FEV}_{1} / \mathrm{FVC}, \%$ & $77.5(1.4)$ & $75.9(1.8)$ & $64.2(1.1)$ & $55.1(1.9)$ & $37.2(2.3)$ & $35.9(4.8)$ & $64.2(2.9)$ \\
\hline \multirow[t]{2}{*}{$\% \mathrm{FEV}_{1}, \%$} & 112.1 & 100.5 & $91.1(2.5)$ & $64.7(2.4)$ & $41.8(1.5)$ & $33.3(4.0)$ & $69.8(4.2)$ \\
\hline & $(5.2)$ & $(3.7)$ & & & & & \\
\hline \%Reversibility in FEV $1, \%$ & $1.7(0.7)$ & $6.0(1.0)$ & $1.6(1.2)$ & $3.1(0.8)$ & $10.5(5.1)$ & $11.7(3.5)$ & $15.6(3.1)$ \\
\hline
\end{tabular}

\section{Spirometry}

Spirometry was performed using an electrical spirometer (Chestgraph Jr. HI-101, CHEST Ltd., Tokyo, Japan) before and 30 minute after inhalation of a bronchodilator (200 $\mu \mathrm{g}$ of salbutamol). Spirometry was performed three times with flow-volume curve maneuvers in each subject, and the best effort of forced vital capacity (FVC) or $\mathrm{FEV}_{1}$ was recorded in accordance with the ATS recommendations (18).

Abbreviation: ATS: American Thoracic Society

\section{Echocardiography}

After the blood test, echocardiography was performed by cardiologists in 32 of the patients with COPD. Diameter of the aorta and left atrium, thickness of the interventricular septum and posterior left ventricular wall and \% ejection fraction were measured. The pulmonary artery systolic pres- sure (PASP) was analyzed in terms of tricuspid regurgitation peak velocity (TRPV) and right atrial pressure (RAP) using a color-Doppler technique (PASP=4×TRPV+RAP) (19).

\section{Statistical analysis}

All data are expressed as the mean and standard error of the mean (SEM). Plasma BNP levels are also expressed as BNP/age, because previous studies have demonstrated that plasma BNP levels are affected by aging as well as gender (20). Unpaired t-tests were used for comparison among groups and corrected by Mann-Whitney U test. Correlations were determined by Spearman's rank correlation test. For the outcomes of the 3-year follow-up study, the mortality and proportion of subjects who had at least one episode of exacerbation were compared between groups by Fisher's exact test, and the period until first exacerbation and death were analyzed by log rank test. All comparisons were two- 
Table 1. Continued

\begin{tabular}{|c|c|c|c|c|c|c|c|}
\hline \multicolumn{8}{|l|}{ Comorbidity, $\mathrm{n}$} \\
\hline Hypertension & 0 & 0 & 2 & 3 & 1 & 3 & 0 \\
\hline Diabetes Mellitus & 4 & 0 & 1 & 2 & 0 & 4 & 0 \\
\hline $\begin{array}{l}\text { Biochemistry, mean } \\
\text { (SEM) }\end{array}$ & \multicolumn{6}{|c|}{ Biochemistry, mean } & \\
\hline Peripheral & $151(20)$ & $171(37)$ & $154(29)$ & $158(25)$ & $197(39)$ & $186(44)$ & $784(413)$ \\
\hline \multicolumn{8}{|l|}{ eosinophils, $/ \mathrm{mm}^{3}$} \\
\hline serum C-reactive & $1.1(0.4)$ & $1.3(0.4)$ & $2.4(1.1)$ & $2.5(0.6)$ & $3.1(1.0)$ & $6.6(3.3)$ & $0.8(0.2)$ \\
\hline \multicolumn{8}{|l|}{ protein, mg/L } \\
\hline \multirow[t]{2}{*}{ serum IgE, IU/L } & $159(49)$ & $363(101)$ & $536(433)$ & $226(91)$ & $389(191)$ & $126(38)$ & 2,214 \\
\hline & & & & & & & $(1,521)$ \\
\hline $\begin{array}{l}\text { Artery blood gas } \\
\text { analysis* }\end{array}$ & & & & & & & \\
\hline $\mathrm{PaO}_{2}$, Torr & $91.6(2.7)$ & $89.1(1.6)$ & $93.7(2.4)$ & $79.9(1.8)$ & $69.5(2.4)$ & $66.6(3.3)$ & $84.8(7.1)$ \\
\hline \multicolumn{8}{|l|}{ Treatment, $\mathrm{n}$} \\
\hline Long-term oxygen & 0 & 0 & 0 & 0 & 0 & 7 & 0 \\
\hline \multicolumn{8}{|l|}{ therapy } \\
\hline Home non-invasive & 0 & 0 & 0 & 0 & 0 & 1 & 0 \\
\hline \multicolumn{8}{|l|}{ ventilation } \\
\hline Long-acting & 0 & 0 & 1 & 12 & 14 & 8 & 0 \\
\hline \multicolumn{8}{|l|}{ anticholinergics } \\
\hline Long-acting & 0 & 0 & 0 & 3 & 4 & 6 & 10 \\
\hline \multicolumn{8}{|l|}{ beta-agonists } \\
\hline Slow & 0 & 0 & 0 & 4 & 5 & 5 & 8 \\
\hline \multicolumn{8}{|l|}{ theophylline } \\
\hline Regular use of & 0 & 0 & 0 & 3 & 4 & 5 & 10 \\
\hline \multicolumn{8}{|l|}{ Inhaled corticosteroids } \\
\hline $\begin{array}{l}\text { Regular use of oral } \\
\text { corticosteroids }\end{array}$ & 0 & 0 & 0 & 0 & 0 & 0 & 6 \\
\hline
\end{tabular}

Data for age, smoking index, body mass index, spirometry, and biochemistry are expressed as mean and SEM. Other categories are expressed as the number of subjects. * Arterial blood gas analysis was performed while breathing room air in non-smokers $(\mathrm{n}=11)$, smokers $(\mathrm{n}=10)$, and in patients with mild (stage I, $\mathrm{n}=10$ ), moderate (stage II, $\mathrm{n}=18$ ), severe (stage III, $\mathrm{n}=12$ ) and very severe (stage IV, $\mathrm{n}=11$ ) COPD, and patients with severe asthma $(n=10)$.

$\mathrm{M}=$ male, $\mathrm{F}=$ female, $\mathrm{N}=$ non-smokers, $\mathrm{Ex}=$ experienced smokers, $\mathrm{C}=$ current smokers, $\mathrm{SEM}=$ standard error of mean, $\mathrm{FVC}=$ force volume capacity, $\mathrm{FEV}_{1}=$ force expiratory volume in 1 second, $\mathrm{IgE}=$ immunoglobulin $\mathrm{E}$.

\% Reversibility in $\mathrm{FEV}_{1}=\left(\mathrm{FEV}_{1}\right.$ at post-bronchodilator $-\mathrm{FEV}_{1}$ at pre-bronchodilator $) /$ $\mathrm{FEV}_{1}$ at pre-bronchodilator $\times 100$. 
a

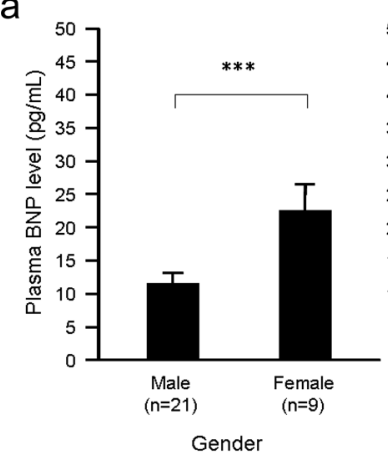

C

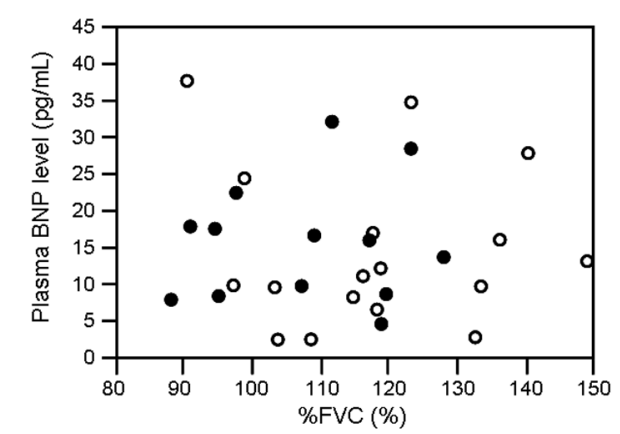

b

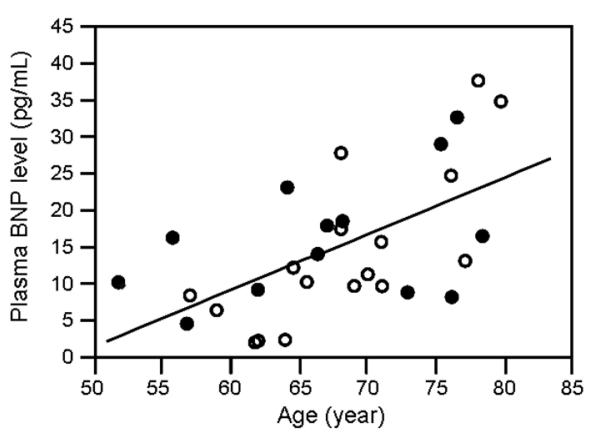

d

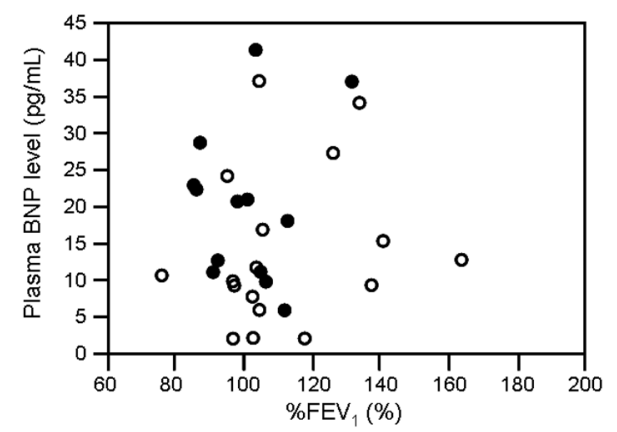

Figure 1. Plasma BNP levels in normal subjects. Normal subjects comprised 21 males and 9 females and 17 non-smokers (clear circles) and 13 former smokers (solid circles). a) Data are expressed as mean \pm SEM. Comparison of plasma BNP levels between male and female normal subjects (left). Comparison of plasma BNP levels between non- and former smokers (right). b) Correlation between plasma BNP level and age. c) Correlation between plasma BNP level and \% FVC. d) Correlation between plasma BNP level and \% FEV 1 * *** $\mathbf{p}<0.0001$.

tailed, and differences at $\mathrm{p}<0.05$ were considered significant. Data analysis was conducted using JMP for Windows, version 12 (SAS Institute Inc., Cary, NC).

\section{Results}

\section{Plasma BNP levels in normal subjects}

The plasma BNP level (mean \pm SEM) in normal subjects was $14.8 \pm 2.7 \mathrm{pg} / \mathrm{mL}$. Gender comparison showed that the plasma BNP level in 9 women $(22.6 \pm 3.9 \mathrm{pg} / \mathrm{mL})$ was significantly higher than that in 21 males $(11.5 \pm 1.4 \mathrm{pg} / \mathrm{mL})(\mathrm{p}<$ 0.0001) (Fig. 1a). There was no difference in plasma BNP levels between 17 non-smokers $(14.1 \pm 2.6 \mathrm{pg} / \mathrm{mL})$ and 13 smokers $(15.7 \pm 2.3 \mathrm{pg} / \mathrm{mL}$ ) (Fig. 1b). Plasma BNP level was correlated significantly with age $(\mathrm{r}=0.59, \mathrm{p}=0.0006)$ (Fig. 1b), but not with \%FVC $(\mathrm{p}>0.05)$ or $\% \mathrm{FEV}_{1}(\mathrm{p}>0.05)$ (Figs. 1c, 1d).

\section{Plasma BNP levels in patients with COPD and asthma}

The plasma BNP level (mean \pm SEM) in COPD patients $(41.0 \pm 6.6 \mathrm{pg} / \mathrm{mL})$ was significantly higher than that in normal subjects $(14.8 \pm 2.7 \mathrm{pg} / \mathrm{mL})$ and patients with asthma $(17.4 \pm 4.5 \mathrm{pg} / \mathrm{mL}) \quad(\mathrm{p}<0.0001$ and $\mathrm{p}<0.05$, respectively $)$ (Fig. 2). The plasma BNP level in COPD patients was significantly higher than in non-smokers and smokers, and increased with disease severity $(\mathrm{p}<0.01)$ (Fig. 2).
To eliminate factors associated with age, the index of plasma BNP level/age was calculated, and was shown to be higher in COPD patients than in normal subjects and asthmatic patients, and to increase with disease severity (data not shown).

Correlation between plasma BNP level and \%FEV arterial blood gas parameters, cardiac function, and pulmonary artery systolic pressure (PASP)

The plasma BNP level was significantly correlated with $\%$ ejection fraction $(\mathrm{r}=-0.41, \mathrm{p}=0.0197)$ and PASP $(\mathrm{r}=0.5$, $\mathrm{p}=0.004$ ), but not with $\% \mathrm{FEV}_{1}$ after the use of a bronchodilator and $\mathrm{PaO}_{2}$ (Fig. 3). There was also a significant negative correlation between \% ejection fraction and PASP ( $r=-$ 0.49, $\mathrm{p}=0.0069$ ). However, there was no correlation between plasma BNP level and $\mathrm{PaCO}_{2}$ (data not shown).

\section{Plasma BNP level and previous hospital admission for COPD exacerbation}

Twenty-one of the 60 patients with COPD had a history of one or more hospital admissions for exacerbation. The plasma BNP level (mean \pm SEM) in subjects who had a history of hospital admission for exacerbation $(66.2 \pm 16.7 \mathrm{pg}$ / $\mathrm{mL})$ was significantly higher than in those who did not (27.4 $\pm 3.2 \mathrm{pg} / \mathrm{mL})(\mathrm{p}=0.0039)$ (Fig. 4). 


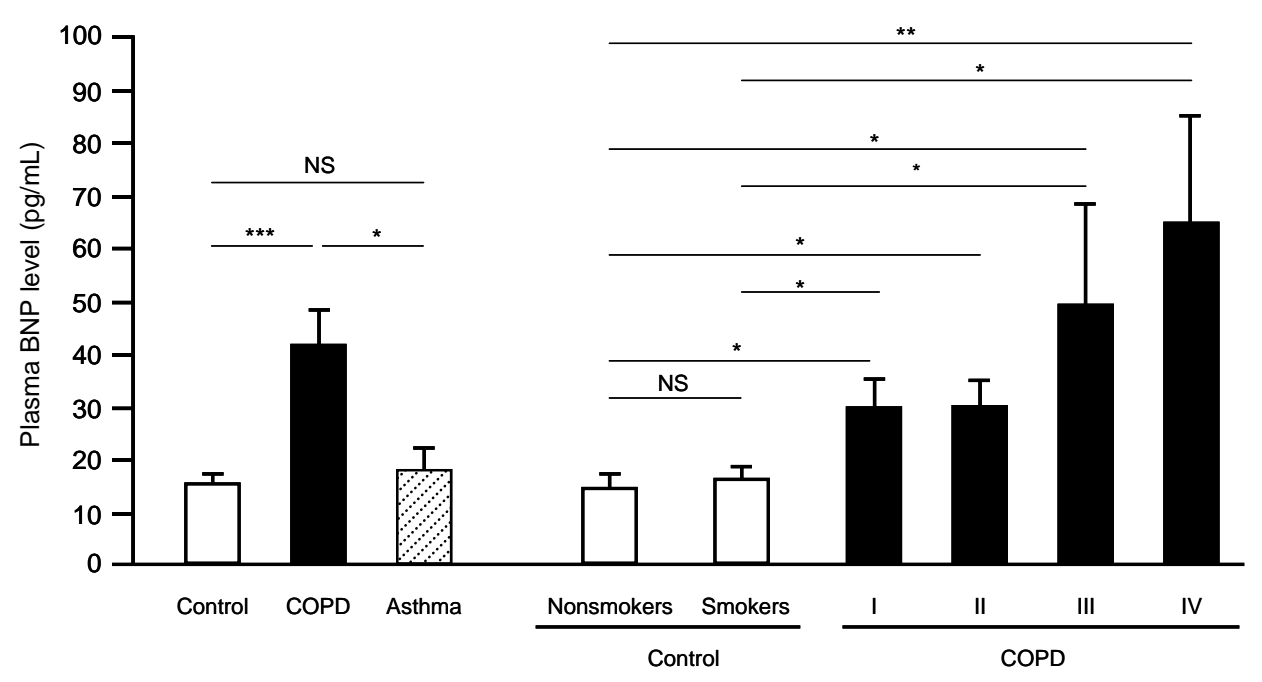

Figure 2. Plasma BNP levels in patients with COPD in comparison to normal subjects and asthmatics, and in relation to COPD severity. All data are expressed as mean \pm SEM. Plasma BNP levels in normal subjects, and in patients with COPD and severe persistent asthma, are shown as clear, solid, and hatched bars, respectively (left), and are compared between groups of different disease severity, and between non- and former smokers (right). ${ }^{*} \mathbf{p}<0.05, * * \mathbf{p}<0.001$, and $* * * \mathbf{p}<0.0001$.

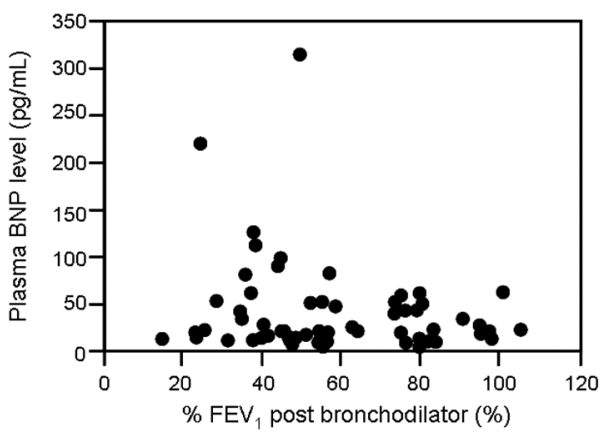

C

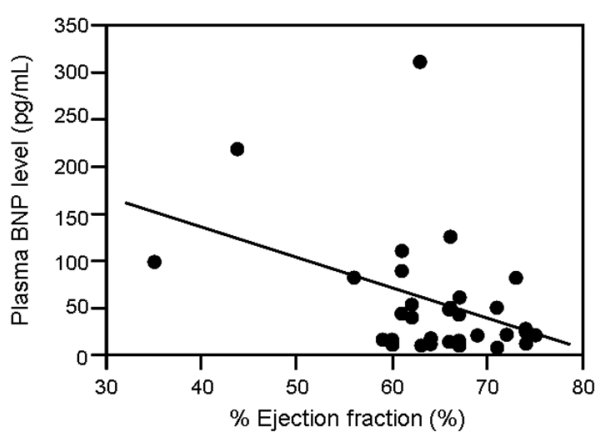

$\mathrm{b}$

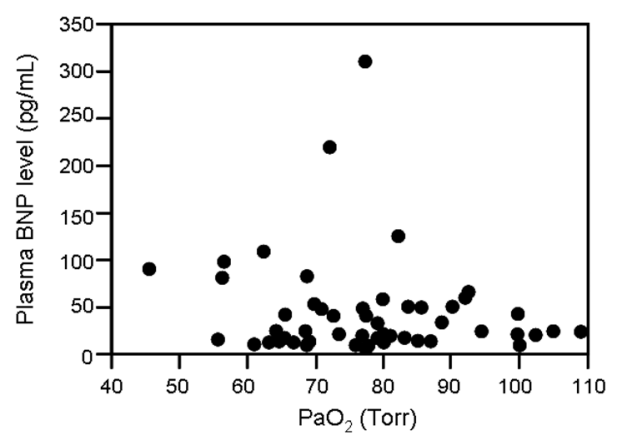

d

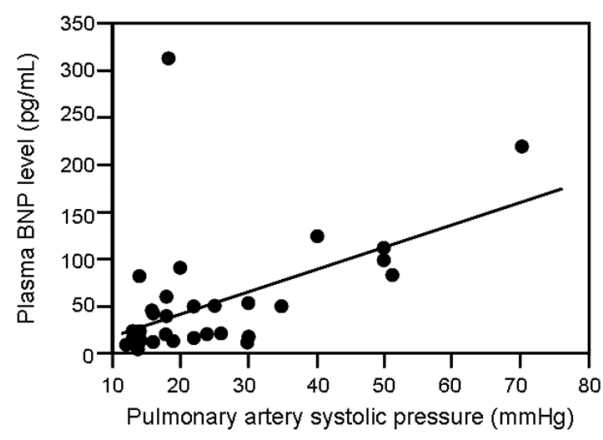

Figure 3. Correlation between plasma BNP levels and $\% \mathrm{FEV}_{1}$, arterial blood gas parameters, cardiac function, and pulmonary artery systolic pressure. a) Correlation between plasma BNP level and \% $\mathrm{FEV}_{1}(\mathrm{n}=60)$. b) Correlation between plasma $\mathrm{BNP}$ level and $\mathrm{PaO}_{2}(\mathrm{n}=51)$. c) Correlation between plasma BNP level and \% ejection fraction $(n=32)$ d) Correlation between plasma BNP level and pulmonary artery systolic pressure $(n=32)$. $n=$ tested number.

\section{Prospective evaluation of mortality and exacerba- tion in COPD patients}

We calculated the cut-off value of the plasma BNP level $(>34.2 \mathrm{pg} / \mathrm{mL}$ as high BNP) as the mean $+2 \mathrm{SD}$ from data of normal subjects. The numbers of COPD patients with high and low BNP levels at the first visit were 22 and 38, respectively. During the 3 years of follow-up, two subjects died; one due to lung cancer and the other to respiratory tract infection. COPD was very severe in both of these patients, and the plasma BNP levels were 111.0 and $124.8 \mathrm{pg} / \mathrm{mL}$. There was no difference in mortality between patients with 
high and low BNP levels. The proportion of patents with mild, moderate, severe, and very severe COPD who suffered at least one episode of exacerbation was $0 \%(0 / 12), 5 \%(1 /$ $20), 31.3 \%(5 / 16)$, and $58.3 \%$ (7/12), respectively. The proportion of subjects with exacerbation increased significantly with disease severity $(\mathrm{p}<0.05)$. The proportion $(36.4 \%, 8 / 22)$ of subjects with exacerbation who had high BNP levels tended to be higher than that of patients with low BNP levels $(13.2 \%, 5 / 38)$ (relative risk $2.764,95 \%$ confidence interval $1.030-7.412, \mathrm{p}=0.0519)$.

Univariate analysis showed that the period until initial COPD exacerbation was significantly shorter in patients with higher severity than in those with lower severity $(\mathrm{p}<$ 0.0001) (Fig. 5a). The period until initial exacerbation in patients with high BNP levels was also significantly shorter than in those with low BNP levels $(\mathrm{p}=0.0285)$ (Fig. 5b).

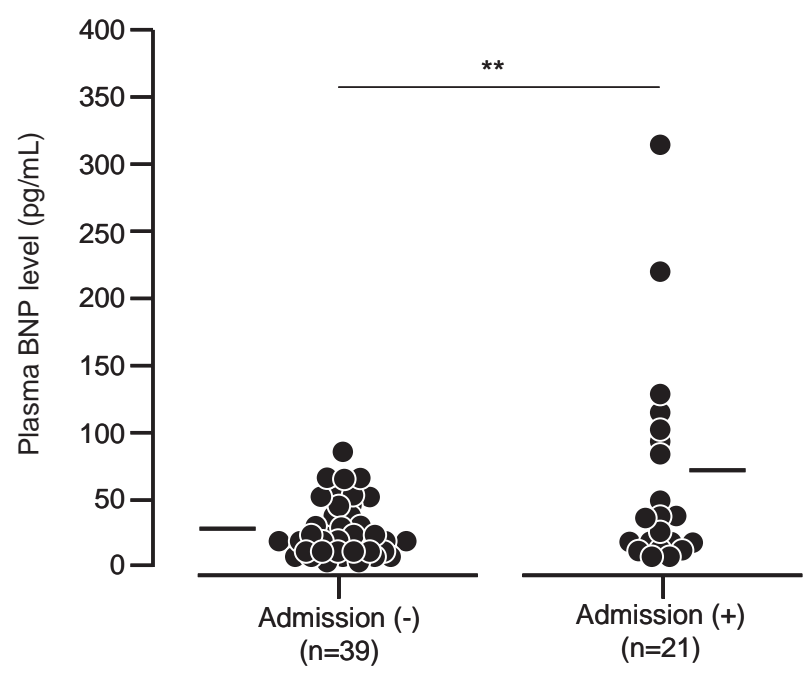

Figure 4. Plasma BNP levels and previous admission for COPD exacerbation. Mean plasma BNP levels in subjects admitted previously for exacerbation are compared to those without such episodes. $* * \mathbf{p}<0.001$.

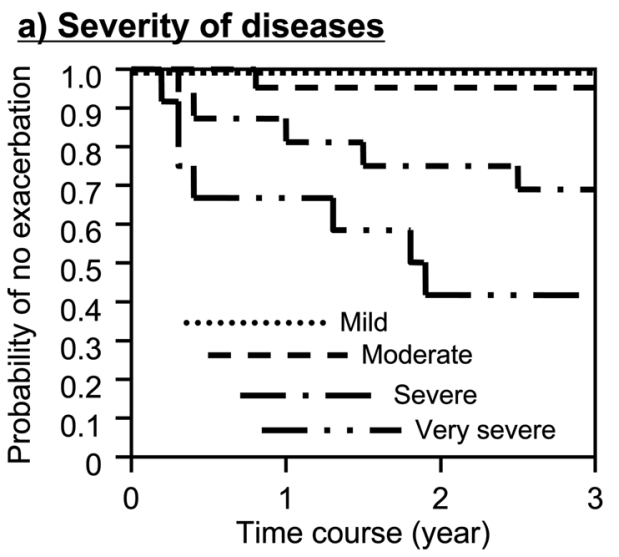

Multivariate logistic regression analysis showed that the hazard ratios in the more severe group and high BNP group for the period until initial exacerbation were 19.03 (95\% CI 3.72 - 347.60, p<0.0001) and 3.78 (95\% CI $1.24-12.66, \mathrm{p}=$ $0.0194)$, respectively.

Abbreviation: SD: standard deviation

\section{Change in plasma BNP levels in patients with COPD exacerbation}

Seventeen episodes of exacerbation (severity of exacerbation: mild $n=6$; moderate $n=7$; severe $n=3$ ) were identified in 13 COPD patients. All three episodes of severe and one of the episodes of moderate exacerbation required hospital admission. Plasma BNP levels (mean \pm SEM) during exacerbation $(79.9 \pm 16.2 \mathrm{pg} / \mathrm{mL})$ were significantly higher than in patients with stable COPD $(41.2 \pm 8.7 \mathrm{pg} / \mathrm{mL}) \quad(\mathrm{p}=0.004)$, with the exception of 2 episodes when the levels were not higher. Plasma BNP levels during severe exacerbation tended to be higher than in episodes of mild and moderate exacerbation (Fig. 6).

\section{Discussion}

In the present study, we demonstrated that plasma BNP levels in patients with stable COPD who did not have any symptoms or physical findings of $\mathrm{PH}$ or cor pulmonale were significantly higher than those of healthy subjects and patients with severe asthma, and the level increased significantly with disease severity. These results were also confirmed when factors related to age and gender were eliminated, because it is known that plasma BNP levels are affected by these factors. Plasma BNP levels in subjects who had a history of admission for exacerbation were significantly higher than in those who did not. During 3 years of prospective follow-up, there was no marked correlation between high plasma BNP levels and mortality due to COPD. The proportion of subjects with exacerbation who had a high BNP level tended to be higher than that of subjects

\section{b) Plasma BNP levels}

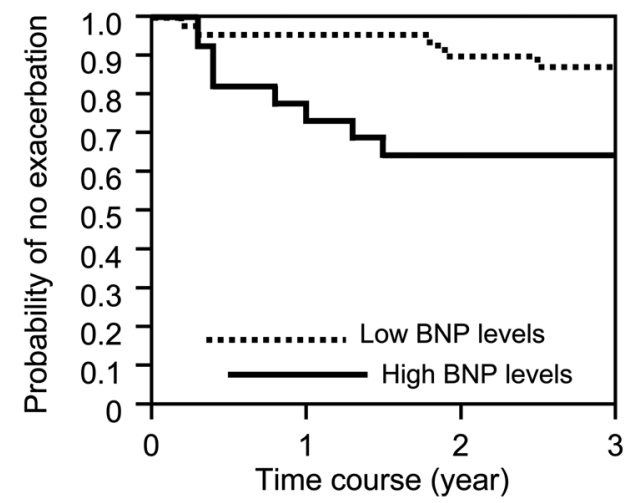

Figure 5. Timing of initial exacerbation determined prospectively. Kaplan-Meier estimation of the probability of remaining exacerbation-free time. The period until initial exacerbation was compared in relation to COPD severity $(p<0.0001)$ (a) and the cut-off level of plasma $B N P(p=0.0285)$ (b) using the log rank test. 


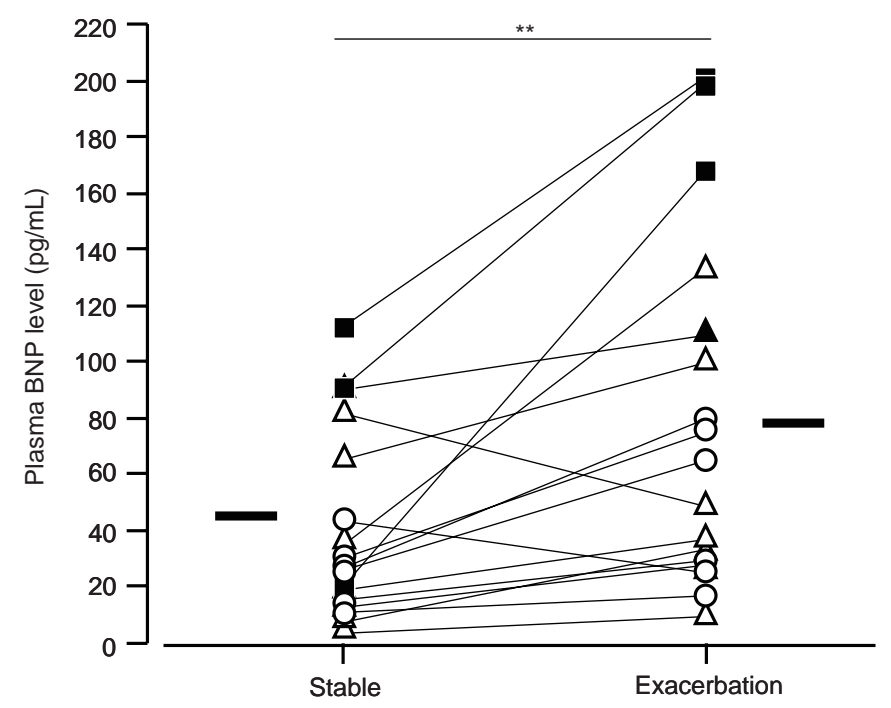

Figure 6. Changes in plasma BNP level in COPD exacerbation. Plasma BNP levels during episodes of mild, moderate and severe exacerbation are expressed as clear circles, triangles and boxes, respectively. Solid triangles and boxes represent episodes requiring hospital admission. $* * \mathbf{p}<0.001$.

with a low BNP level, and the period until initial exacerbation in subjects with a high BNP level was also significantly shorter than in those with a low level. In addition, we demonstrated that the plasma BNP level was elevated when exacerbation occurred.

Exacerbation affects the quality of life and prognosis of patients with COPD (1). Previous studies have suggested that risk factors for exacerbation requiring hospitalization include more severe disease, low $\mathrm{FEV}_{1}$, functional dyspnea, advanced age, presence of cardiovascular comorbidities, low body mass index, and low physical activity (21-23). Examination of the plasma BNP level would be helpful for identifying the probability of exacerbation, although the impact might be less in patients with less severe disease. Multivariate logistic regression analysis suggested that the presence of a high plasma BNP level could be an independent risk factor for exacerbation in stable COPD. With regard to the cut-off value, plasma BNP levels used for the screening of heart failure have ranged from 50 to $100 \mathrm{pg} / \mathrm{mL}$ (24-27), and one systematic review has reported that an increase in the plasma BNP level by $100 \mathrm{pg} / \mathrm{mL}$ is associated with a $35 \%$ increase in the relative risk of death due to cardiovascular disease (28). An elevated BNP level is also associated with the presence of $\mathrm{PH}$ and is a risk factor of death in patients with pulmonary fibrosis and $\operatorname{COPD}(12-14,29,30)$. However, the cut-off level of plasma BNP for estimation of mortality and exacerbation in patients with stable COPD without significant $\mathrm{PH}$ or cor pulmonale has been unclear. In the present study, the period until initial COPD exacerbation in subjects with high plasma BNP levels was significantly shorter than in those with low BNP levels, when a cut-off value of $34.2 \mathrm{pg} / \mathrm{mL}$ was employed. It is possible that patients with stable COPD who have high plasma BNP levels may have some underlying disorder of circulation or cardiac function.

The mechanism responsible for the high plasma BNP level in patients with stable COPD is not well understood. In the present study, there was no significant correlation between plasma BNP level and $\% \mathrm{FEV}_{1}$. However, there were significant differences in plasma BNP levels among patients at different stages when data for subjects with hypoxemia were added. There was no significant correlation between plasma BNP level and $\mathrm{PaO}_{2}$ at rest. This may be because the severity of COPD according to the guidelines is defined by $\% \mathrm{FEV}_{1}$ alone rather than by $\mathrm{PaO}_{2}$. Weak but significant correlations were identified between plasma BNP level and \% ejection fraction, and PASP. Furthermore, there was also a significant negative correlation between $\%$ ejection fraction and PASP in the present study. Previous studies have suggested that chronic overload of pulmonary pressure induces left ventricular filling impairment with a leftward septal shift, leading to decreased left ventricular function $(31,32)$. Taken together, these findings suggest that the plasma BNP level reflects the presence of secondary PH and/or left ventricular failure in COPD. Another explanation for the high plasma BNP levels in subjects with COPD might be associated with exercise or sleep disordered breathing. Fujii and coworkers (33) have already demonstrated that BNP levels are markedly increased with exercise in subjects with COPD. It is also known that some subjects with COPD have overlap syndrome with obstructive sleep apnea, and that the proportion of $\mathrm{PH}$ patients with overlap syndrome is higher than that of patients with obstructive sleep apnea alone, and with COPD alone $(34,35)$. Subjects with PH have elevated BNP levels. Therefore, disordered breathing during sleep might lead to high plasma BNP levels in subjects with COPD $(14,34,35)$. In the present study we excluded subjects who had a history of, or the presence of symptoms and/or physical evidence of $\mathrm{PH}$ or cor pulmonale. High PASP (>35 mmHg) as defined by echocardiography was observed in $5(15.6 \%)$ of 32 subjects with COPD. These subjects were identified as having latent $\mathrm{PH}$. Echocardiography therefore seems useful for the evaluation of $\mathrm{PH}$ and cardiac function in COPD patients, even if they do not have symptoms or physical evidence of significant $\mathrm{PH}$ and cardiac failure.

In addition, plasma BNP levels were elevated when exacerbations occurred in some subjects, as Stolz and coworkers have demonstrated (36). Exacerbation is associated with a transient decrease in expiratory flow, which, in some cases, takes weeks to return to the baseline, although there are several different causes $(1,37)$. Radical decreases in expiratory flow may lead to increased air-trapping and hyperinflation of the lung. It is possible that such hyperinflation is associated with decreased cardiac function and may lead to an increase of plasma BNP level during exacerbation (38). Furthermore, it is well known that pulmonary embolism results in secondary PH (39-41). Tillie-Leblond and coworkers (42) reported a $25 \%$ prevalence of pulmonary embolism in patients with COPD hospitalized for severe exacerbation of 
unknown origin. Elevated plasma BNP levels in some subjects with exacerbation might be associated with pulmonary embolism, although conclusive evidence for this is lacking (43).

There were some limitations to the study. First, the correlation between high plasma BNP levels and mortality in COPD patients was not investigated. Stolz and coworkers (36) also reported that BNP levels failed to adequately predict short-term and long-term mortality rates in patients with exacerbation. It is possible that the sample size may have been too small or the study period too short. The present study was performed at a single institution, and a multicenter trial may be more appropriate. Second, it is still unknown whether monitoring of plasma BNP levels contributes to the management of patients with stable COPD. Plasma BNP levels were not measured at regular time points. Third, we did not verify the outcome of subjects with high plasma BNP levels when early intervention was initiated. This means that the efficacy of early diagnosis and intervention based on measurement of plasma BNP levels is still unknown.

In conclusion, we have demonstrated that plasma BNP levels are elevated in patients with stable COPD. A high plasma BNP level was shown to be an independent risk factor for exacerbation, but not mortality, in this patient cohort. Our results suggest that there is a correlation between a high plasma BNP level and PH or left ventricular dysfunction, and that the plasma BNP level may be useful for the differential diagnosis from asthma, and as a screening parameter for latent PH or left ventricular dysfunction and the probability of exacerbation. The plasma BNP level appears to be a promising and safe biomarker for the management of patients with COPD.

\section{Acknowledgement}

We are especially grateful to Dr. Gail M. Gauvreau of the Asthma Research Group, McMaster University, Ontario, Canada, for critical reading of the manuscript.

\section{References}

1. Global Initiative for Chronic Obstructive Lung Disease. Global strategy for the diagnosis, management and prevention of chronic obstructive pulmonary disease. 2006. NHLBI/WHO workshop report. Bethesda, National Heart, Lung and Blood Institute. [online] Accessed November 2006. URL: www.goldcopd.com.

2. Wedzicha JA, Calverley PM, Seemungal TA, et al. The prevention of chronic obstructive pulmonary disease exacerbations by salmeterol/fluticasone propionate or tiotropium bromide. Am J Respir Crit Care Med 177: 19-26, 2008.

3. Calverley PM, Anderson JA, Celli B, et al. Salmeterol and fluticasone propionate and survival in chronic obstructive pulmonary disease. N Engl J Med 356: 775-789, 2007.

4. Oswald-Mammosser M, Weitzenblum E, Quoix E, et al. Prognostic factors in COPD patients receiving long-term oxygen therapy. Importance of pulmonary artery pressure. Chest 107: 1193-1198, 1995.

5. Nocturnal Oxygen Therapy Trial Group. Continuous or nocturnal oxygen therapy in hypoxemic chronic obstructive lung disease. Ann Intern Med 93: 391-398, 1980.

6. Bourge RC, Abraham WT, Adamson PB, et al. Randomized controlled trial of an implantable continuous hemodynamic monitor in patients with advanced heart failure: the COMPASS-HF study. J Am Coll Cardiol 51: 1073-1079, 2008.

7. Shah MR, O'Connor CM, Sopko G, et al. Evaluation Study of Congestive Heart Failure and Pulmonary Artery Catheterization Effectiveness (ESCAPE): design and rationale. Am Heart J 141: 528-535, 2001.

8. Cowie MR, Struthers AD, Wood DA, et al. Value of natriuretic peptides in assessment of patients with possible new heart failure in primary care. Lancet 350 (9088): 1349-1353, 1997.

9. Wei CM, Heublein DM, Perrella MA, et al. Natriuretic peptide system in human heart failure. Circulation 88: 1004-1009, 1993.

10. Mekontso Dessap A, Leon R, Habibi A, et al. Pulmonary hypertension and cor pulmonale during severe acute chest syndrome in sickle cell disease. Am J Respir Crit Care Med 177: 646-653, 2008.

11. Leuchte HH, El Nounou M, Tuerpe JC, et al. N-terminal pro-brain natriuretic peptide and renal insufficiency as predictors of mortality in pulmonary hypertension. Chest 131: 402-409, 2007.

12. Ishii J, Nomura M, Ito M, et al. Plasma concentration of brain na- triuretic peptide as a biochemical marker for the evaluation of right ventricular overload and mortality in chronic respiratory disease. Clin Chim Acta 301: 19-30, 2000.

13. Bando M, Ishii Y, Sugiyama $Y$, et al. Elevated plasma brain natriuretic peptide levels in chronic respiratory failure with cor pulmonale. Respir Med 93: 507-514, 1999.

14. Leuchte HH, Baumgartner RA, Nounou ME, et al. Brain natriuretic peptide is a prognostic parameter in chronic lung disease. Am J Respir Crit Care Med 173: 744-750, 2006.

15. Global Initiative for Asthma. Global strategy for asthma management and prevention. [online] Accessed undated November 2006. URL: www.ginasthma.org.

16. Wenzel S. Severe asthma in adults. Am J Respir Crit Care Med 172: 149-160, 2005.

17. Rodriguez-Roisin R. Toward a consensus definition for COPD exacerbations. Chest 117 (5 Suppl 2): 398S-401S, 2000.

18. American Thoracic Society. Standardization of Spirometry, 1994 Update. Am J Respir Crit Care Med 152: 1107-1136, 1995.

19. Kitabatake A, Inoue M, Asao M, et al. Noninvasive evaluation of pulmonary hypertension by a pulsed Doppler technique. Circulation 68: 302-309, 1983.

20. Clerico A, Del Ry S, Maffei S, et al. The circulating levels of cardiac natriuretic hormones in healthy adults: effects of age and sex. Clin Chem Lab Med 40: 371-377, 2002.

21. Niewoehner DE, Lokhnygina $Y$, Rice $K$, et al. Risk indexes for exacerbations and hospitalizations due to COPD. Chest 131: 2028, 2007.

22. Celli BR, Cote CG, Marin JM, et al. The body-mass index, airflow obstruction, dyspnea, and exercise capacity index in chronic obstructive pulmonary disease. N Engl J Med 350: 1005-1012, 2004.

23. Garcia-Aymerich J, Monsó E, Marrades RM, et al. Risk factors for hospitalization for a chronic obstructive pulmonary disease exacerbation. EFRAM study. Am J Respir Crit Care Med 164: 10021007, 2001.

24. Ng LL, Loke I, Davies JE, et al. Identification of previously undiagnosed left ventricular systolic dysfunction: community screening using natriuretic peptides and electrocardiography. Eur J Heart Fail 5: 775-782, 2003.

25. Harrison A, Morrison LK, Krishnaswamy P, et al. B-type natri- 
uretic peptide predicts future cardiac events in patients presenting to the emergency department with dyspnea. Ann Emerg Med 39: 131-138, 2002.

26. Maisel AS, Krishnaswamy P, Nowak RM, et al. Rapid measurement of B-type natriuretic peptide in the emergency diagnosis of heart failure. N Engl J Med 347: 161-167, 2002.

27. Cowie MR, Struthers AD, Wood DA, et al. Value of natriuretic peptides in assessment of patients with possible new heart failure in primary care. Lancet 350 (9088): 1349-1353, 1997.

28. Doust JA, Pietrzak E, Dobson A, et al. How well does B-type natriuretic peptide predict death and cardiac events in patients with heart failure: systematic review. BMJ 330 (7492): 625, 2005. URL: www.bmj.com.

29. Abroug F, Ouanes-Besbes L. Detection of acute heart failure in chronic obstructive pulmonary disease patients: role of B-type natriuretic peptide. Curr Opin Crit Care 14: 340-347, 2008.

30. Leuchte HH, Neurohr C, Baumgartner R, et al. Brain natriuretic peptide and exercise capacity in lung fibrosis and pulmonary hypertension. Am J Respir Crit Care Med 170: 360-365, 2004.

31. Shena M, Clini E, Errera D, et al. Echo-doppler evaluation of left ventricular impairment in chronic cor pulmonale. Chest 109: 1446-1451, 1996.

32. Jessup M, St John Sutton M, Weber KT, et al. The effect of chronic pulmonary hypertension on left ventricular size, function and interventricular septal motion. Am Heart J 113: 1114-1122, 1987.

33. Fujii $T$, Otsuka $T$, Tanaka $S$, et al. Plasma endothelin-1 level in chronic obstructive pulmonary disease: relationship with natriuretic peptide. Respiration 66: 212-219, 1999.

34. Weitzenblum E, Chaouat A, Kessler R, et al. Overlap syndrome: obstructive sleep apnea in patients with chronic obstructive pulmo- nary disease. Proc Am Thorac Soc 5: 237-241, 2008.

35. Chaouat A, Weitzenblum E, Krieger J, et al. Association of chronic obstructive pulmonary disease and sleep apnea syndrome. Am J Respir Crit Care Med 151: 82-86, 1995.

36. Stolz D, Breidthardt T, Christ-Crain M, et al. Use of B-type natriuretic peptide in the risk stratification of acute exacerbations of COPD. Chest 133: 1088-1094, 2008.

37. Seemungal TA, Donaldson GC, Bhowmik A, et al. Time course and recovery of exacerbations in patients with chronic obstructive pulmonary disease. Am J Respir Crit Care Med 161: 1608-1613, 2000.

38. Vassaux C, Torre-Bouscoulet L, Zeineldine S, et al. Effects of hyperinflation on the oxygen pulse as a marker of cardiac performance in COPD. Eur Respir J 32: 1275-1282, 2008.

39. Bonderman D, Skoro-Sajer N, Jakowitsch J, et al. Predictors of outcome in chronic thromboembolic pulmonary hypertension. Circulation 115: 2153-2158, 2007.

40. de Perrot M, Fadel E, McRae K, et al. Evaluation of persistent pulmonary hypertension after acute pulmonary embolism. Chest 132: 780-785, 2007.

41. van Wolferen SA, Grunberg K, Vonk Noordegraaf A. Diagnosis and management of pulmonary hypertension over the past 100 years. Respir Med 101: 389-398, 2007.

42. Tillie-Leblond I, Marquette CH, Perez T, et al. Pulmonary embolism in patients with unexplained exacerbation of chronic obstructive pulmonary disease: prevalence and risk factors. Ann Intern Med 144: 390-396, 2006.

43. Suntharalingam J, Goldsmith K, Toshner M, et al. Role of NTproBNP and 6MWD in chronic thromboembolic pulmonary hypertension. Respir Med 101: 2254-2262, 2007.

(C) 2009 The Japanese Society of Internal Medicine http://www.naika.or.jp/imindex.html 